Rowan University

Rowan Digital Works

Stratford Campus Research Day

25th Annual Research Day

May 6th, 12:00 AM

\title{
Ring Based Wearable Bioelectrical Impedance Analyzer for Body Fat Estimation
}

\author{
Muhammad Usman \\ Rowan University \\ Adarsh Gupta \\ Rowan University \\ Wei Xue \\ Rowan University
}

Follow this and additional works at: https://rdw.rowan.edu/stratford_research_day

Part of the Community Health and Preventive Medicine Commons, Investigative Techniques

Commons, Nutritional and Metabolic Diseases Commons, and the Other Analytical, Diagnostic and

Therapeutic Techniques and Equipment Commons

Let us know how access to this document benefits you - share your thoughts on our feedback form.

Usman, Muhammad; Gupta, Adarsh; and Xue, Wei, "Ring Based Wearable Bioelectrical Impedance Analyzer for Body Fat Estimation" (2021). Stratford Campus Research Day. 70.

https://rdw.rowan.edu/stratford_research_day/2021/may6/70

This Poster is brought to you for free and open access by the Conferences, Events, and Symposia at Rowan Digital Works. It has been accepted for inclusion in Stratford Campus Research Day by an authorized administrator of Rowan Digital Works. 


\section{Introduction}

Obesity is the most serious public health problem because it is linked to cardiovascular diseases.

Measuring fat mass is necessary to study the obesity epidemic

- Fat mass can be estimated by measuring impedance of the human body.

\section{Motivation}

- Body fat analyzers play a vital role in the world of e-health today.

Current commercial body fat analyzers are large and bulky.

- Analyzers providing accurate measurements are very expensive.
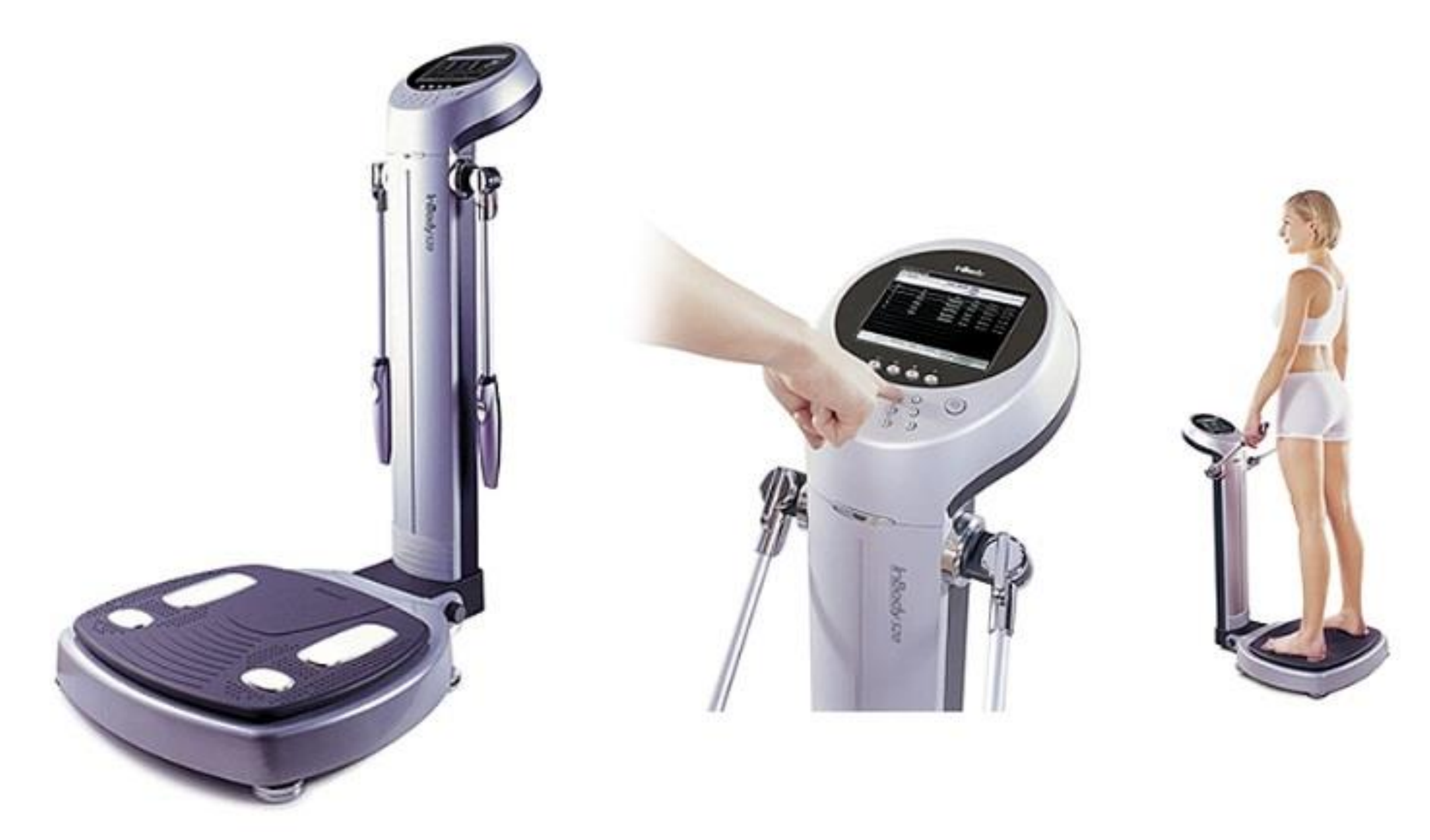

Commercial bioelectrical impedance analyzer.

\section{Objectives}

- Wearable bioelectrical impedance analyzer for body fat estimation.

- To develop a miniaturized, lightweight, inexpensive, convenient and accurate system.

\section{System Architecture}

Two pair of electrodes for interfacing human body.

- A sensor and controller module for signal processing and wireless communication via Bluetooth.

A smartphone application for user interface and record management.

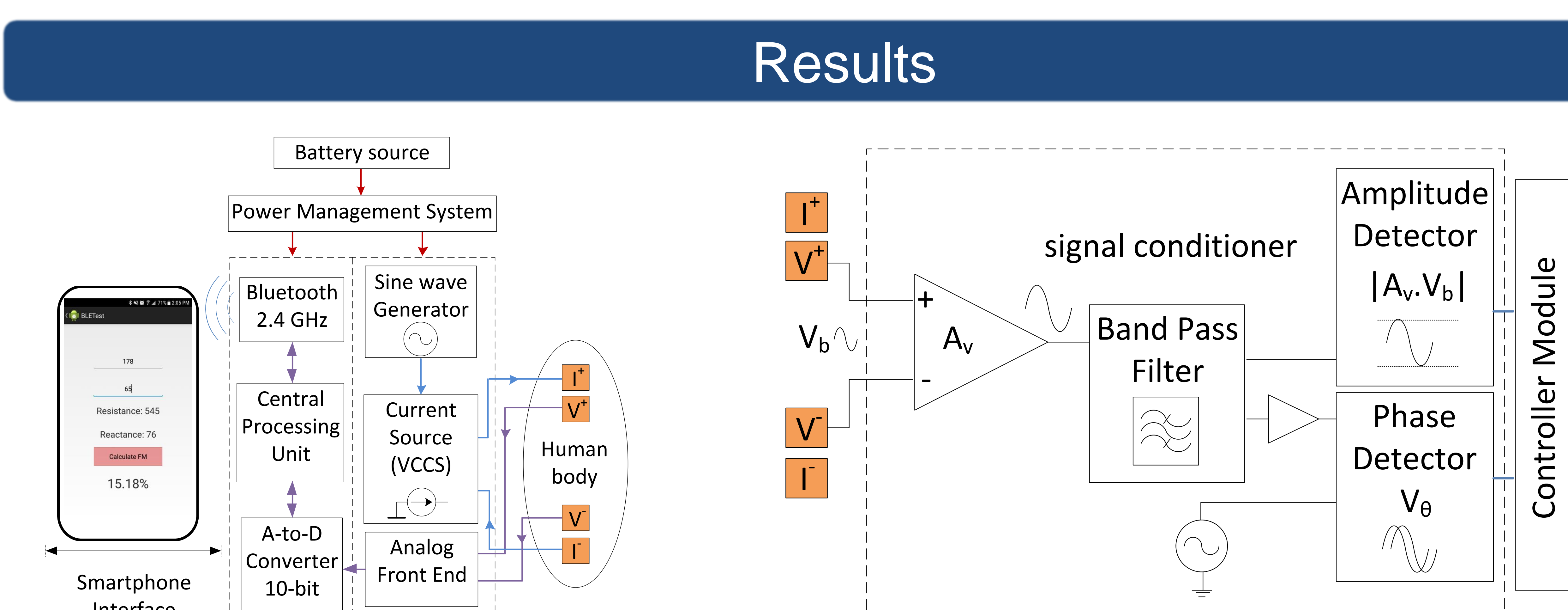

Analog Front End

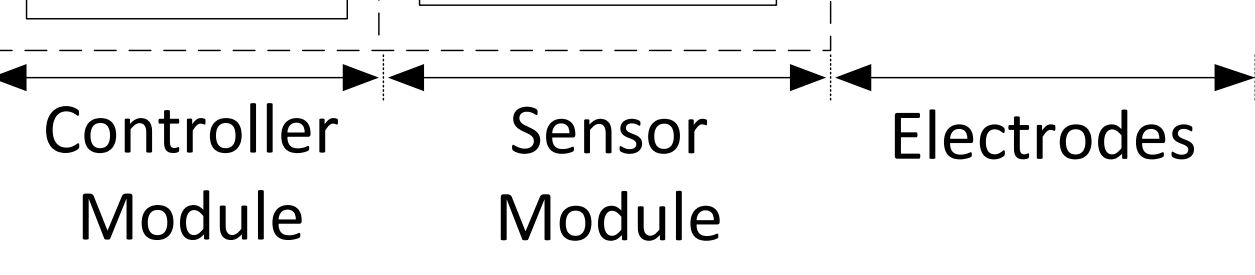

Simplified block diagram of the designed bioelectrical impedance Elaboration of the designed analog front end. This front end is filterins amplitude and shase processing such as amplification,

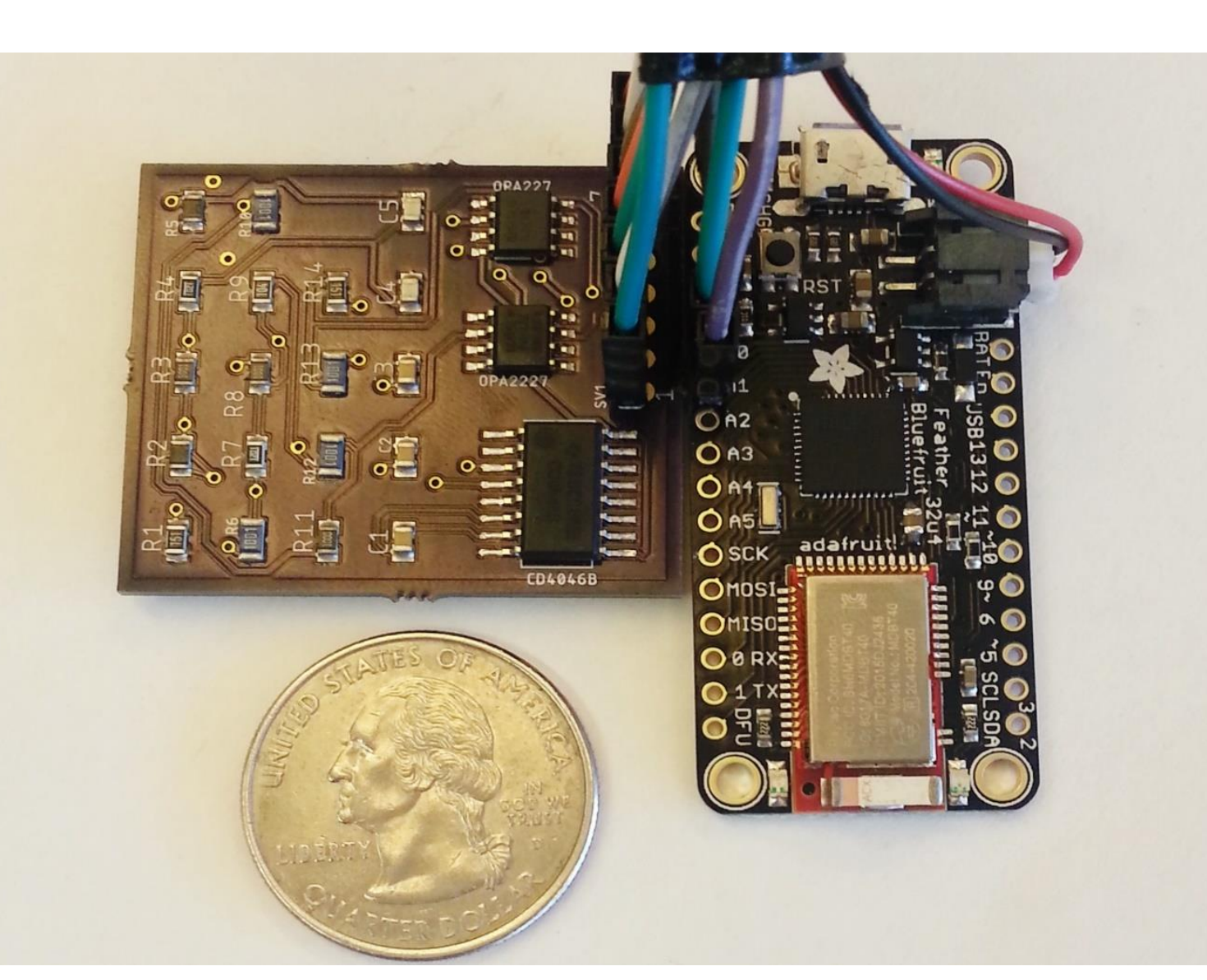

Photograph of the sens module interface.

$$
\mathrm{FFM}_{\mathrm{kg}}=-4.104+0.518 \times \frac{\mathrm{Height}_{\mathrm{m}} \mathrm{m}^{2}}{\text { Resistance }}+0.231 \times \text { Weight }_{\mathrm{kg}}
$$
$+0.130 \times$ Reactance $+4.229 \times$ Gender

$$
\mathrm{FM}_{\%}=\left(1-\frac{\mathrm{FFM}_{\mathrm{kg}}}{\text { Weight }}\right) \times 100 \%
$$

Current source vs load resistance

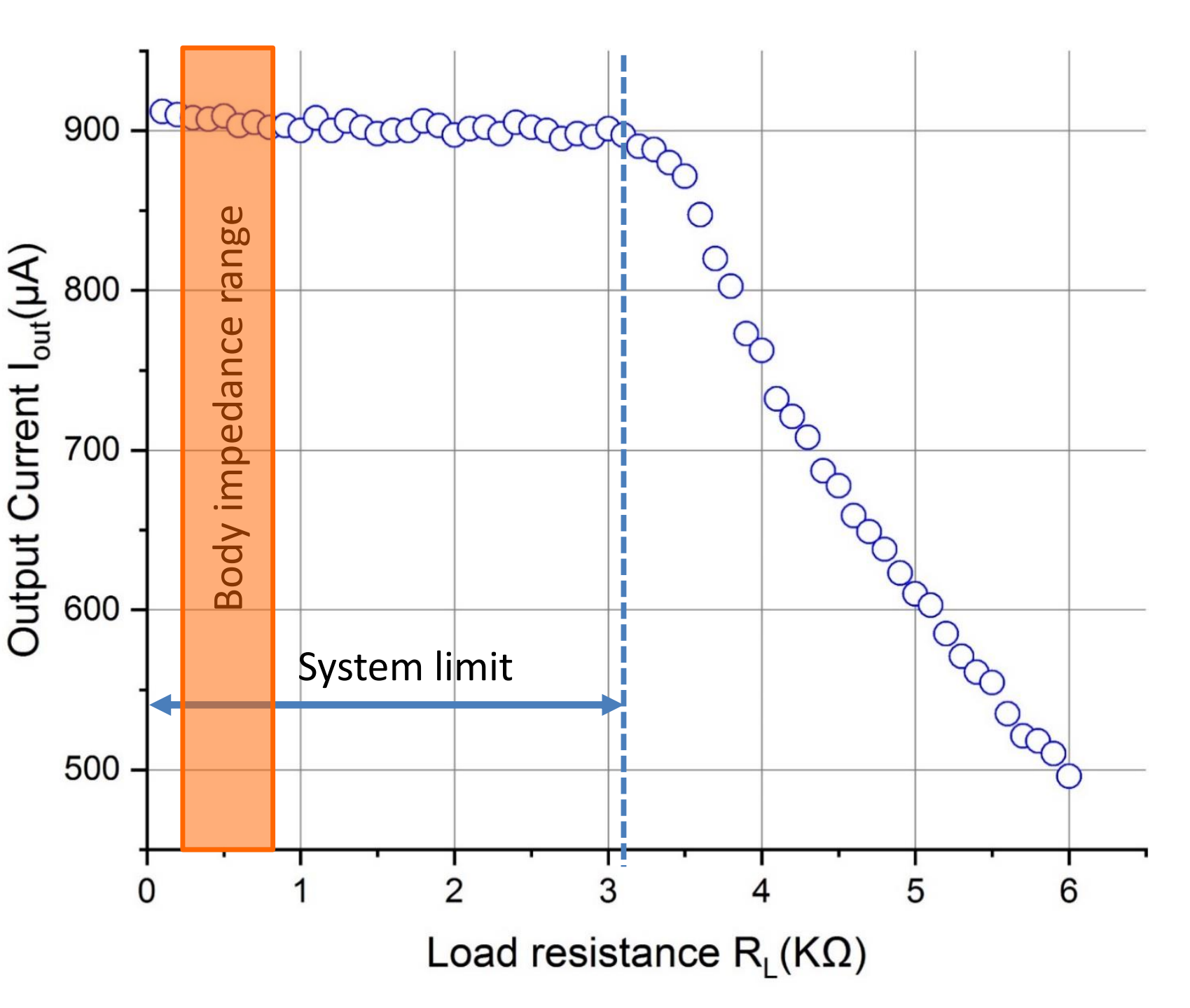

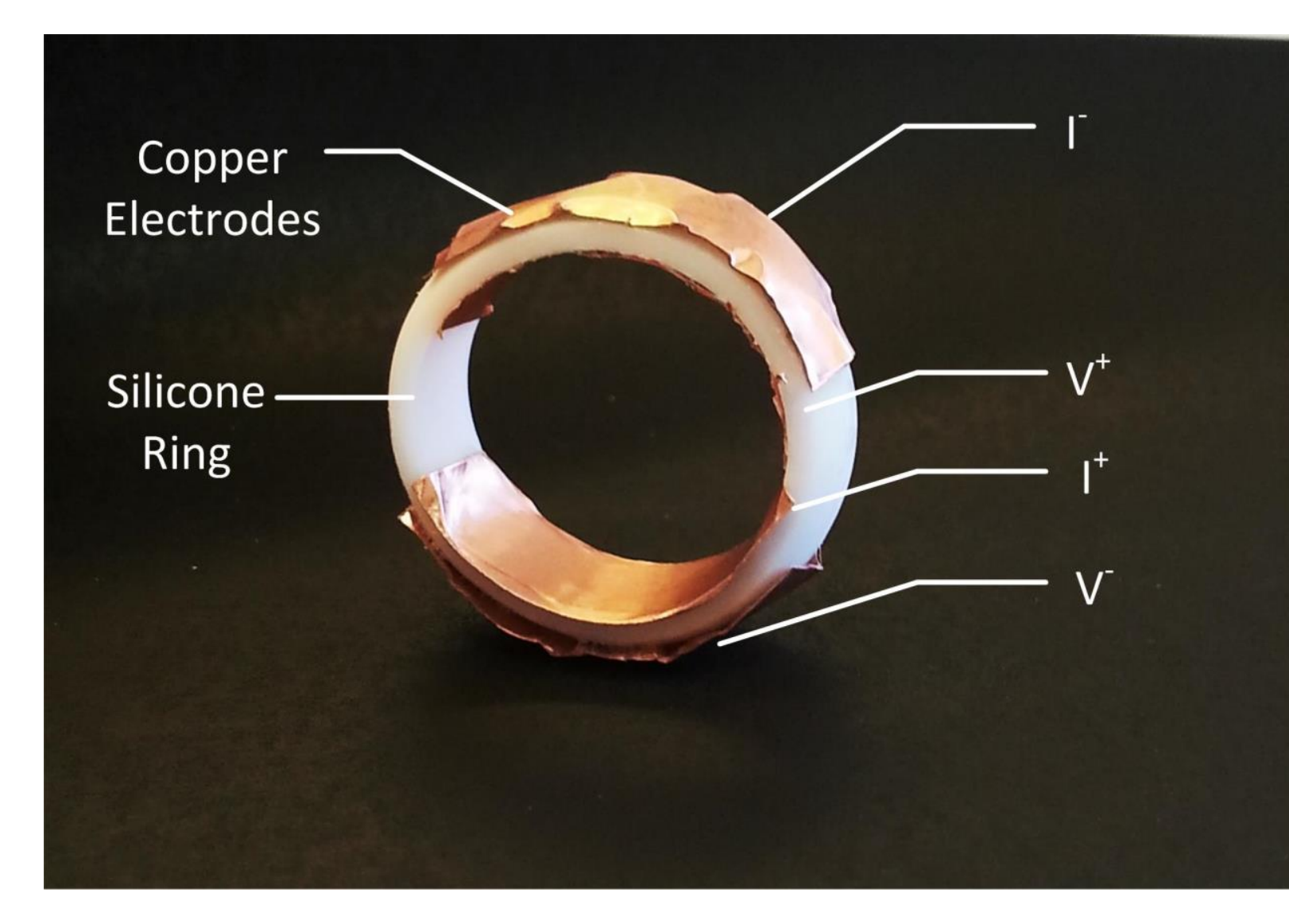
Silicone ring with copper electrodes. Current is applied through source electrodes $\left(I^{-1}, I^{+}\right)$while enclosure.
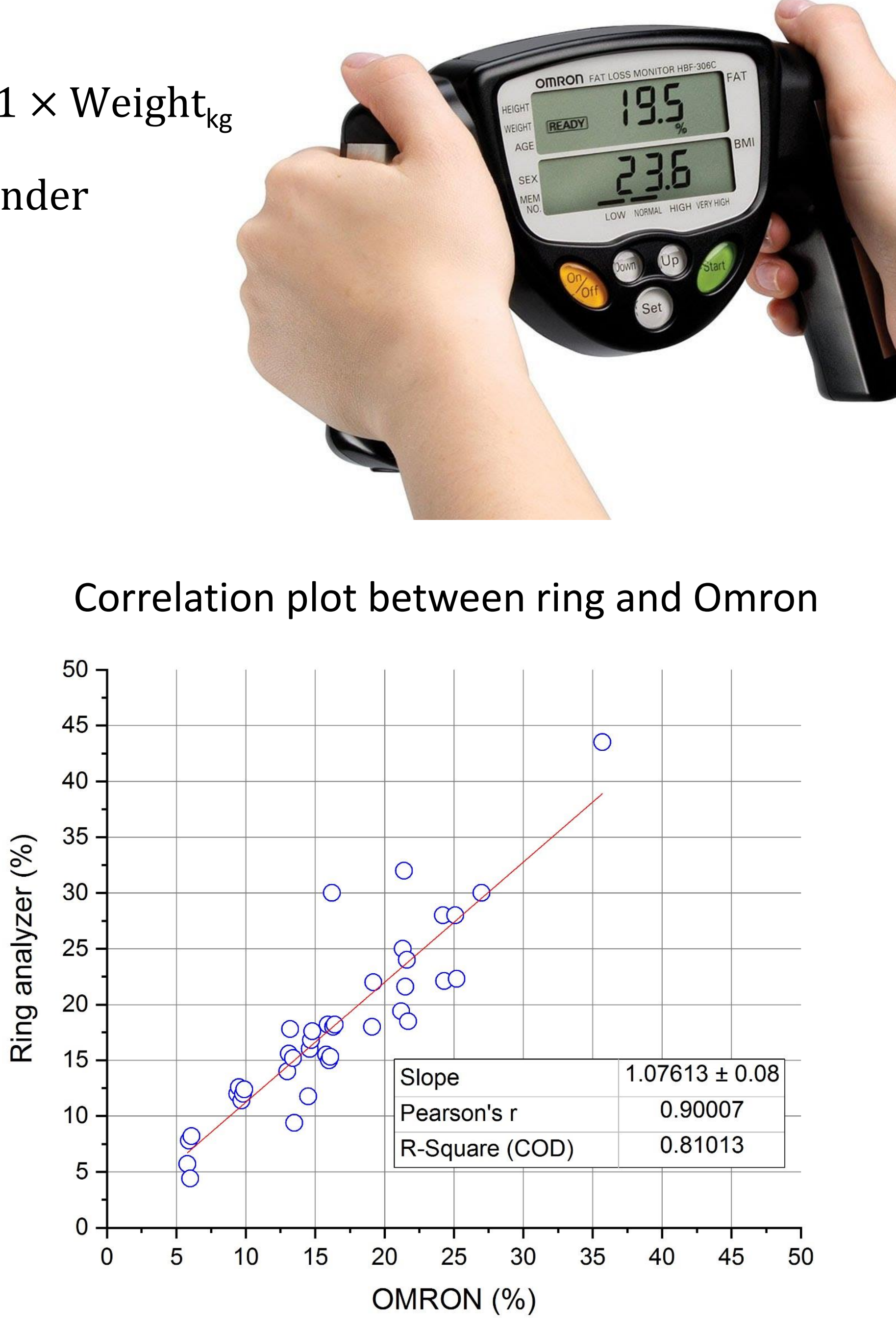

(b)

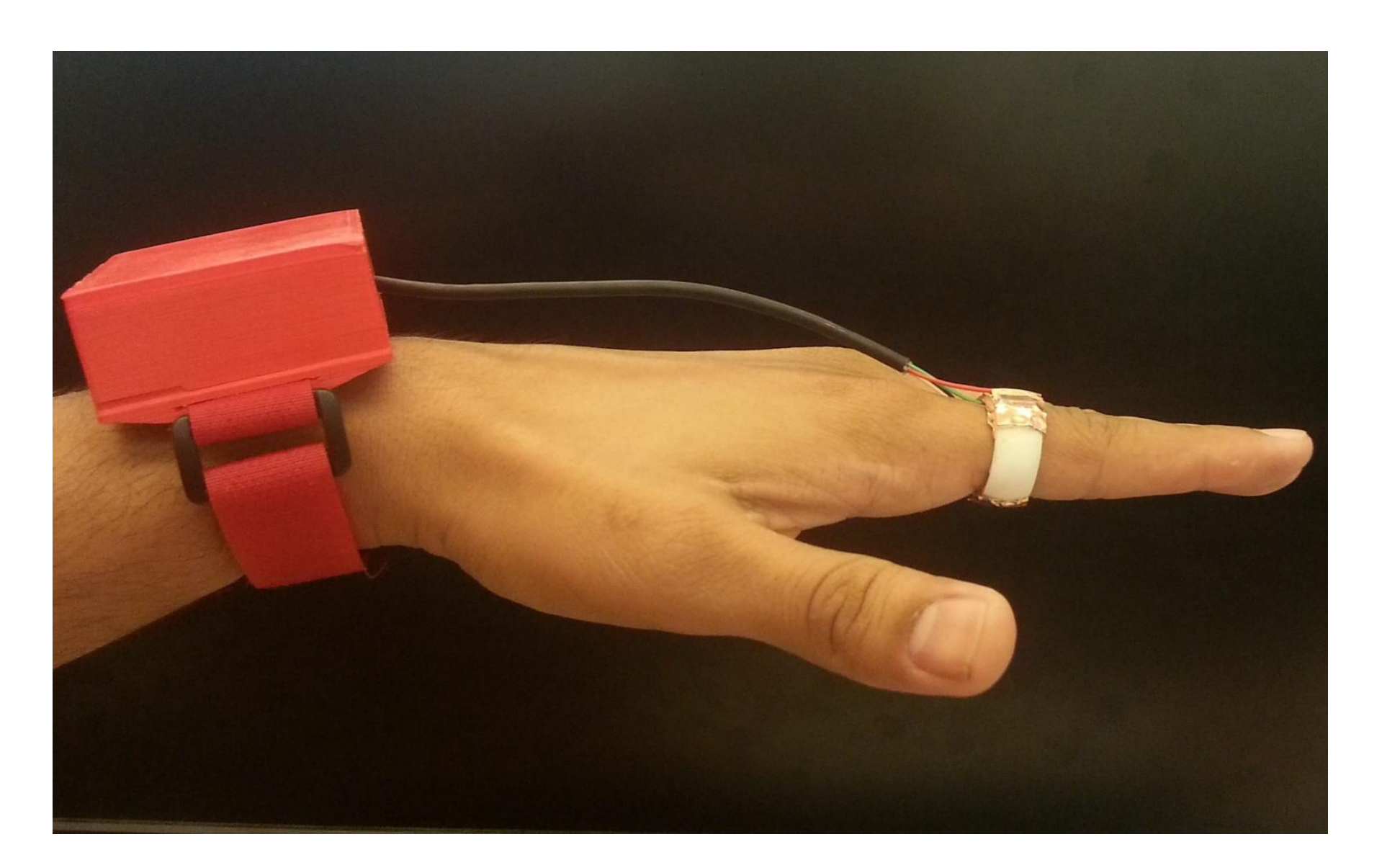
OMRON hand held upper
body fat monitor (HBF-306C) Weight: $0.5 \mathrm{~kg}$ Dimension: $9 \times 2 \times 6$ inches Sensor technology: Hand to hand Battery: 2 AAA
Electrodes: Aluminum (a) Safe amount of current $(900 \mu \mathrm{A})$ is applied to the human body through a voltage controlled current source. Since body resistance is less than $1 \mathrm{k} \Omega$, the system will work very accurate for this range.

(b) Body fat correlation plot between commercial (OMRON) and the designed ring wearable device. The results indicate that there is a strong correlation between the devices with a correlation coefficient of $0.9\left(R^{2}=0.8101, R=0.9\right)$.

(c) Bland-Altman plot for our device under test (DUT) and the reference monitor. It can be seen that 38 out of 40 subjects lie within $95 \%$ limit of agreement

\section{Future work}

- Miniaturizing the electronic circuit and eventually the overall device.

- Validation for body water, muscle mass and skeletal mass estimation.

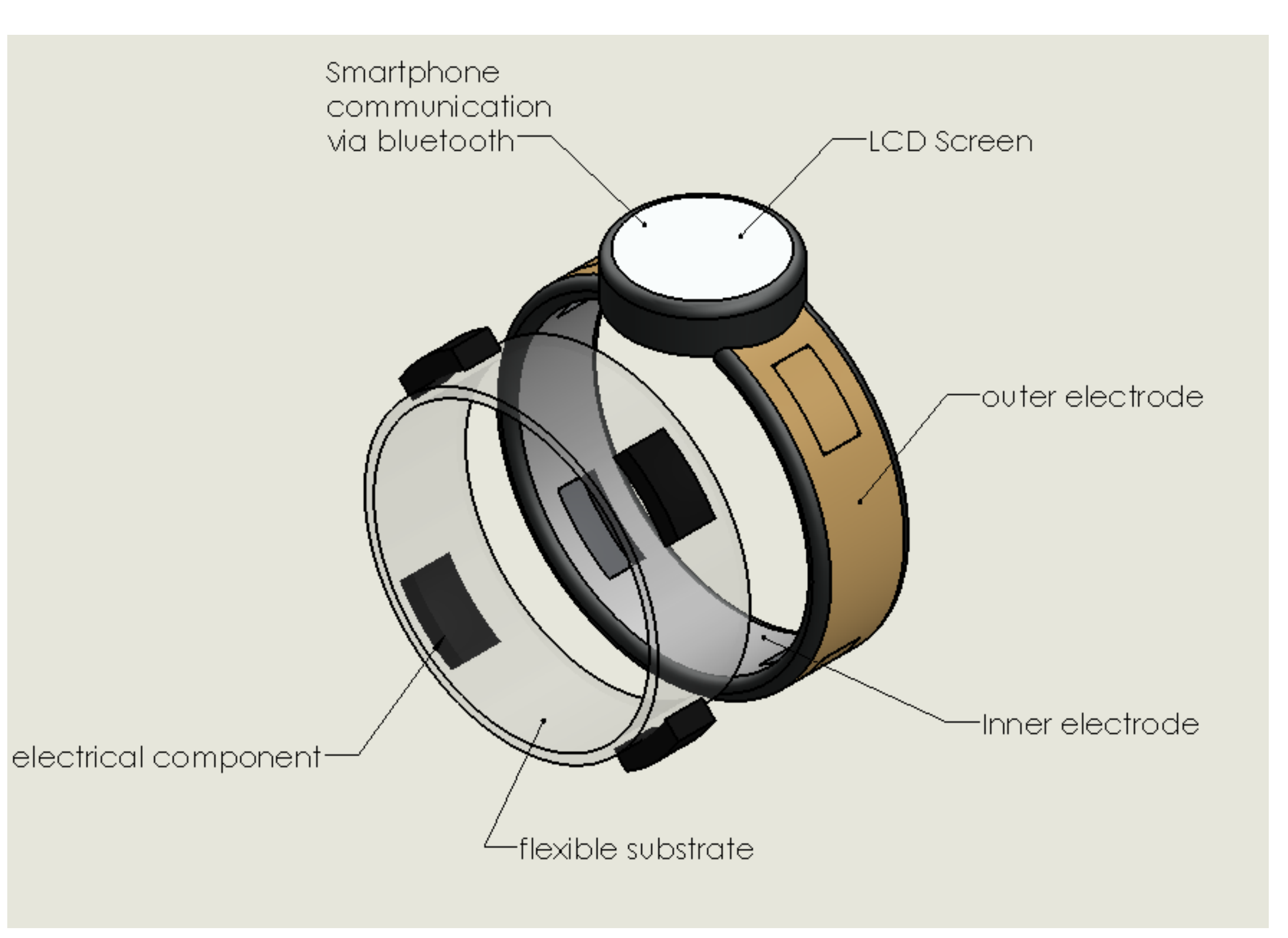

\section{Conclusions}

- A novel bioelectrical impedance analyzer for body fat estimation.

- Device validated for 40 healthy human subjects against commercial analyzer.

- Great potential to replace commercial analyzers for wearable real-time body fat monitoring.

\section{Acknowledgements}

We would like to thank our clinic team of undergraduates. Carla Silvestri, Anwar Noel and Bryan Regn.

\section{References}

[1] J. R. Macdonald and E. Barsoukov, "Impedance spectroscopy: theory, experiment, and applications," History, vol. 1,2005

[2] U. G. Kyle, I. Bosaeus, A. D. De Lorenzo, P. Deurenberg, M. Elia, J. M. Gómez, et al., "Bioelectrical impedance analysis - part I: review of principles and methods," Clinical nutrition, vol. 23, pp. 1226-1243, 2004.

[3] D. S. Holder, Electrical impedance tomography: methods, history and applications: CRC Press, 2004.

4] R. F. Kushner, "Bioelectrical impedance analysis: a review of principles and applications," J Am Coll Nutr, vol. 11, pp. 199-209, 1992. 